\title{
Remembering Professor David BenEzra, M.D., Ph.D., 1942-2008
}

\author{
Igal Gery • Jorge L. Alio
}

Received: 28 July 2010 / Accepted: 6 September 2010 / Published online: 17 November 2010

(C) The Author(s) 2010. This article is published with open access at Springerlink.com

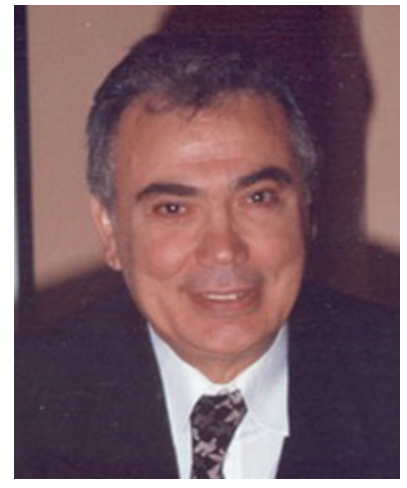

David was my first Ph.D. student, joining my newly established lab in 1966 at the Hebrew UniversityHadassah Medical School in Jerusalem. He was accepted at that time to the Medical School, after spending 1 year as a student in another Faculty. David was born in Morocco and immigrated to Israel with his family in 1956. The family settled in a small village and David had to commute daily to attend school. After serving the mandatory tour of duty in the Israeli military, he came to the Hebrew

I. Gery $(\bowtie)$

Laboratory of Immunology, National Eye Institute, NIH,

Bethesda, MD 20892, USA

e-mail: geryi@nei.nih.gov

J. L. Alio

Department of Ophthalmology, Miguel Hernandez University,

Alicante, Spain

\section{J. L. Alio}

Vissum Corporacion Oftalmologica,

Alicante, Spain

e-mail: jlalio@vissum.com
University, determined to attend the medical school, despite the many hurdles he had to overcome. David loved scientific research and at that early phase in his career he was already fully committed to becoming a physicianscientist, and getting a Ph.D. along with his M.D. degree was an obvious approach. It was a pleasure having him in the lab, a young man full of enthusiasm, original thinking, and fantastic dexterity and capacity to perform at the bench. We quickly established a close friendship and David became a part of my family. After completing his Ph.D. in 1969, he established an immunology lab in the Department of Oncology at Hadassah Hospital, but lucky for all of us, he then met and married Judy, the daughter of Professor Michaelson, the renowned ophthalmologist. Professor Michaelson introduced David to the exciting world of ophthalmology and David shifted his enthusiasm and scientific curiosity to learn about the wonders of the eye.

After completing his residency in ophthalmology, David was sent by the State of Israel and Hadassah Hospital, to help patients with eye diseases in Ethiopia and Malawi. After returning to Jerusalem, he was invited by Dr. Carl Kupfer, the founder of the National Eye Institute (NEI), with a mission to establish a new lab dealing with ocular immunology. David then contacted me with a suggestion to join the NEI, as an immunologist in the new lab he established. I accepted the offer and David introduced me to the amazing organ, the eye, a decade after I introduced him to the exciting world of immunology. Once again, David and I could collaborate and keep being in touch continuously; particularly during a sabbatical he spent at the NEI, the annual ARVO, and other meetings.

Back at the Hadassah Hospital, David focused his clinical efforts on pediatric ophthalmology. He founded a clinical Unit and established a lab where he could carry out research related to his clinical activities and other scientific 
issues he was interested in. One topic he had always been excited about dealt with angiogenesis, a process that received little attention at that time, but its importance for ophthalmology was realized by Professor Michaelson, who hypothesized then that the angiogenic process is mediated by a molecule he named "Factor X". David took over this study, developing new methods to dissect the process and analyzing a large number of compounds for their capacity to inhibit angiogenesis. Decades later, "Factor X," was identified to be "VEGF", a molecule that is currently the target of successful therapies of major eye diseases. Other studies David carried out had dealt with a wide range of topics that included uveitis and the involvement of inflammation in eye diseases, immunosuppressive agents, drug delivery, unique issues of pediatric ophthalmology, as well as genetics of eye disease. More recently, David collaborated with Francine Behar-Cohen, developing novel molecular biology approaches for treatment of eye disease.

David was an outstanding ophthalmologist, excelling in ocular surgery, an area in which he often challenged traditional concepts and introduced innovative ideas. He saved vision of a countless number of patients, mostly children. His reputation attracted patients from all over Israel, as well as other countries in the Middle East. He was devoted to his patients and their families and his office walls were covered with their letters of appreciation.

David's achievements were well recognized by the ophthalmological community. He was invited to serve as a Professor at the Universities and Hospitals in Paris and as a Visiting Professor in several universities in Europe and the USA and as a keynote speaker in numerous meetings around the globe. He received several major scientific awards, including the Alcon Research Award (1988). He served on the editorial boards of five journals and was the author of five books, more than 200 peer-reviewed articles, and a number of chapters in books.

David devoted much of his time and energy to promote international sharing of knowledge and information on ophthalmology and vision research. He conceived the idea of an international organization that would unite ophthalmologists and vision scientists, and together with Jorge Alio, he founded the International Ocular Inflammation Society (IOIS), as described below in detail by Jorge. Other major achievements have been the convening of the Michaelson symposia on ocular circulation and neovascularization and being the Chairman and the organizer of five international panels of experts who authored the guidelines for diagnosis and treatment of major eye conditions. David's contributions were recognized by having him elected to the Presidency of IOIS (1992-1998) and the Mediterranean Ophthalmological Society (1998-2000), as well as membership on numerous international scientific committees.
Fig. 1 The cover page of the first international symposium on ocular inflammation organized in Alicante in 1990

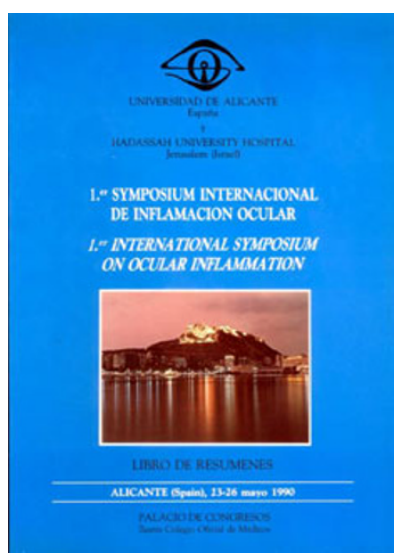

\section{David BenEzra and the creation of the International Ocular Inflammation Society}

The idea of starting the international symposium on ocular inflammation occurred in a meeting that took place between Jorge Alio and David BenEzra in 1989, during the initial launch of the use of cyclosporine in ophthalmology. Jorge and David met there for the first time and this marked the beginning of a longstanding friendship. At that time, the launch of cyclosporine A in Spain and the new topical antiinflammatory non-steroidal medications created a space, in the opinion of Jorge, for an international meeting in which the use of new pharmacological agents and a comprehensive review of the issues related to immunology, inflammation, and ophthalmology could take place. With these ideas, the first international symposium on ocular inflammation was organized in Alicante in 1990 (Fig. 1 shows the cover page of that meeting). The meeting was a great success with over 250 participants and important interactions with the pharmacological industry. A decision was made to organize a second symposium 2 years later in Jerusalem. The meeting in Jerusalem was an even greater success with over 400 participants, a very fruitful scientific program and the creation of a scientific committee. (Fig. 2 shows the cover page of the meeting in Jerusalem). The

Fig. 2 The cover page of the second international symposium on ocular inflammation organized in Jerusalem in 1992

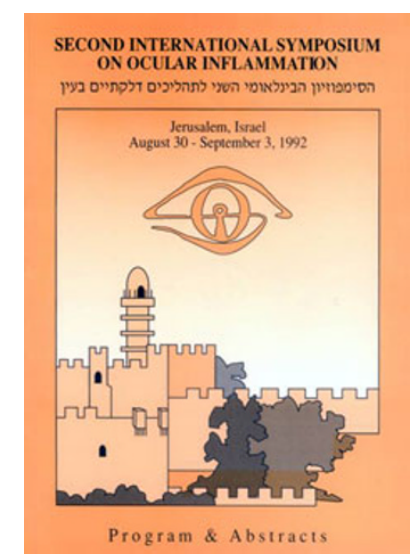


idea of creating a society was on the minds of everybody at the meeting and a decision was made to go ahead with it. The leaders of the society were as follows: David BenEzra, President; Jorge Alio, Chairman; Manabu Mochizuki, General Secretary; Christian de Courten, Treasurer. The society was named IOIS and was created as a charity institution in Spain, with a global projection, bylaws, and with a journal, the Ocular Immunology and Inflammation (OII).

Since then, IOIS meetings have been organized every 2 years, in Fukuoka (1994), London (1996), Amsterdam (1998), Istanbul (2000), Padova (2003), Granada (2005), Paris (2007), and Prague (2009). The IOIS currently has 768 members, from 50 countries and has organized 10 international symposia. The upcoming symposium will take place in Goa, India, in November 2011. Eventually, the partnership with the publisher of the OII journal was discontinued due to certain disagreements. The idea to create a new journal for the Society was on the minds of David and the other leaders of the Society and the decision to do it was made during the Prague symposium, with the new journal being named the Journal of Ophthalmic Inflammation and Infection. It is just to demonstrate that destiny exists that this obituary is published in the first issue of the new journal of the IOIS, so beloved by David BenEzra.

Open Access This article is distributed under the terms of the Creative Commons Attribution Noncommercial License which permits any noncommercial use, distribution, and reproduction in any medium, provided the original author(s) and source are credited. 